\title{
COVID-19 pandemic and dental health care system: An Indian scenario
}

\author{
(1) Shruthi Hegde, (1) Vidya Ajila
}

Nitte (Deemed to be University), AB Shetty Memorial Institute of Dental Sciences (ABSMIDS), Department of Oral Medicine and Radiology, Mangalore, India

\section{Date submitted:}

01.06.2020

Date accepted:

22.06.2020

Online publication date: 15.12.2020

\section{Corresponding Author:}

Dr. Shruthi Hegde MDS, Nitte

(Deemed to be University), AB Shetty Memorial Institute of Dental Sciences (ABSMIDS), Department of Oral Medicine and Radiology, Mangalore, India

drshruthihegde@yahoo.co.in

ORCID:

orcid.org/0000-0002-0744-5593

Keywords: COVID-19, dentistry, dental professionals

\section{Dear Editor,}

In view of the worldwide Coronavirus disease-2019 (COVID-19) pandemic, routine dental procedures have been suspended in most countries in order to avoid virus transmission (1). The major consideration in routine dental practice is the use of aerosol generating procedures using air-rotors, ultrasonic scalers and high pressure 3:1 air syringe. Dentists have a high risk of getting infected from patients and potentially spreading it to their families, other patients and their peers (2). Under these circumstances, it is natural for dentists to develop a fear of being infected by their patients (2). Due to increased contagiousness of SARS-CoV-2, dental healthcare providers have to adopt new protocols to prevent spreading the virus.

On March $17^{\text {th }}, 2020$, the Dental Council of India (DCl) issued an advisory that clinical procedures involving aerosol generation such as Air rotor/Ultrasonic Scalers to be avoided/minimized for the time being and only emergency procedures to be performed (3). Local health authority protocol was different in various states of India. Total closure and telemedicine were suggested. During the lockdown period, most dentists continued their services such as initial consultation and expert opinion to their patients through teledentistry for free of cost. Emergency dental services were provided at hospital settings.

Indian Dental Association (IDA) also highlighted the need to provide task-specific education and training on preventing transmission of infectious agents, including refresher training for all dental personnel (4). The IDA local branches, different state branches and IDA head office arranged webinars for dentists to familiarize them with infection control measures and practice management post lockdown.

Dental professionals in India faced difficulty in the procurement of personal protection equipment due to its unavailability and cost factor. Due to complete closure of dental clinics, private dental practitioners faced financial issues. In order to follow the pre-operative and post-operative infection control protocols, dentists had to invest extra on practice modifications to combat coronavirus disease.

The Ministry of Health and Family Welfare (MoHFW), Government of India, issued guidelines for Dental Professionals regarding COVID-19 pandemic situation on May 19th, 2020. The guidelines have mentioned that dentists, auxiliaries and dental patients are at high risk of cross-infection due to close contact with the patient's oral cavity, saliva, blood, and respiratory tract secretions. Unified guideline was issued by MoHFW because several guidelines were issued by DCI, IDA and other organizations earlier. Dentists were not sure which guidelines to follow. The dental clinics were advised to remain closed in the containment zone and to continue with teledentistry. In the red zone, emergency dental procedures could be performed. The dental clinics in orange and green zone were allowed 
to provide dental consultations and to do only emergency and urgent treatment procedures. All routine and elective dental procedures to be deferred for a later review until new policy/ guidelines were issued (5).

Even though dentistry has been worst hit by COVID-19 pandemic, dental professionals need to stay proactive, composed and provide patients with the best dental care. Most of the dental clinics in India are private establishments and professionals are self-supported. In addition to regular expenditure such as rent of clinic, repayment of loan for clinical establishments, equipment and material cost, lab costs, salary to support staff, utility bills dentists have to invest extra for personal protection equipment and disinfectants to avoid possible spread of COVID-19. This inevitably has to be transferred to patients, which will lead to increase in the cost of treatments. However, dentists find it difficult to raise prices for their low and middle income group of patients. The government advisory recommends only emergency dental treatments in the near future, which will definitely deteriorate financial status of dentists. Considering the overall downfall of economy, general public will also tend to opt for absolutely necessary dental treatments even after the lockdown period. Almost after two months of dilemma, fear and uncertainty, dental professionals have geared up, equipped themselves, and trained themselves to face the new challenge.

\section{Ethics}

Peer-review: Externally and internally peer-reviewed.

\section{Authorship Contributions}

Surgical and Medical Practices: S.H., Concept: S.H., Design: S.H., Data Collection or Processing: S.H., Analysis or
Interpretation: S.H., V.A., Literature Search: S.H., Writing: S.H., V.A.

Conflict of Interest: No conflict of interest was declared by the authors.

Financial Disclosure: The authors declared that this study received no financial support.

\section{References}

1. Dave M, Seoudi N, Coulthard P. Urgent dental care for patients during the COVID-19 pandemic. Lancet. 2020;395:1257.

2. Ahmed MA, Jouhar $\mathrm{R}$, Ahmed $\mathrm{N}$ et al. Fear and Practice Modifications among Dentists to Combat Novel Coronavirus Disease (COVID-19) Outbreak. Int J Environ Res Public Health. 2020;17:2821.

3. Dental Council of India. Precautionary and Preventive Measures to Prevent Spreading of Novel Coronavirus (COVID-19). LastAccessed Date: 23.03.2020. Available from: http://dciindia.gov.in/Admin/NewsArchives/L.No._8855.pdf

4. Indian Dental Association. Indian Dental Association's Preventive Guidelines for Dental Professionals on the Coronavirus Threat. LastAccessed Date: 23.03.2020. Avaiable from: https://www.ida.org.in/pdf/IDA_Recommendations_for_ Dental_Professionals_on_the_Coronavirus_Threat.pdf

5. The Ministry of Health and Family Welfare (MoHFW), Government of India. Guidelines for Dental Professionals in Covid-19 pandemic situation. Last Accessed Date: 23.03.2020. Available from: https://www.mohfw.gov.in/pdf/ DentalAdvisoryF.pdf 